\title{
CONTRATUALISMO E DISPOSIÇÕES MORAIS: UMA CRÍTICA À TESE DA INSEPARABILIDADE DO DIREITO E DA MORAL E À TESE SOBRE A EXISTÊNCIA DE LEIS NATURAIS
}

Marcelo de Araujo*

RESUMO - Discuto aqui duas diferentes interpretações acerca do que seria uma teoria do direito natural (ou jusnaturalismo). A primeira interpretação se caracteriza pela tese da "inseparabilidade" do direito e da moral, ao passo que a segunda se caracteriza pela tese segundo a qual existiriam "leis naturais", i.e. leis cuja existência independeria da existência de instituições humanas. Tento mostrar que as duas teses são falsas. Procuro mostrar inicialmente que a confusão entre as duas teses se deve a uma má compreensão da distinção entre frases do tipo "estar obrigado a", e "ter a obrigação de". Em seguida, mostro como a teoria moral contratualista nos permite resolver de modo satisfatório algumas questões que não são resolvidas adequadamente em nenhuma das duas versões do jusnaturalismo que apresento.

PALAVRAS-CHAVE - Contratualismo. Direito. Jusnaturalismo. Moral. Obrigação.
ABSTRACT - In this paper, I discuss two different interpretations about the thrust of a natural law theory. According to the first interpretation, a natural law theory is one which commits itself to the thesis that the concept of law is "inseparable" from the concept morality, while the second interpretation assumes that there are "natural laws", that is laws the existence of which does not depend on the existence of human institutions. I try to show that both theses are false. I show that the confusion between the two theses stem from a failure to comprehend the distinction between propositions of the kind "to be forced to" and "having the obligation to". Then, I show how moral contractualism enables us to solve some questions which are not satisfactorily solved within the conceptual framework of the two versions of a natural law theory which I present here.

KEY WORDS - Contractualism. Morality. Natural law. Obligation. Right.

O jusnaturalismo (ou teoria do direito natural) pode ser caracterizado como um tipo de teoria jurídica que se compromete com a verdade de pelo menos uma das seguintes teses:

Professor da UERJ / UFRJ e Pesquisador do CNPq. Esta pesquisa contou com apoio financeiro da Fundação Humboldt na Universidade de Konstanz (2007-08).

\begin{tabular}{|l|l|l|l|l|l|}
\hline VERITAS & Porto Alegre & v. 54 & n. 1 & jan./mar. 2009 & p. 161-184 \\
\hline
\end{tabular}


(i) TESE DA INSEPARABILIDADE. O conceito de lei envolve necessariamente o conceito de justiça, i.e. o conceito de direito é inseparável do conceito de moralidade.

(ii) TESE METAFÍSICA. Existem não apenas leis positivas, mas também leis naturais, i.e. leis por meio das quais avaliamos a qualidade moral das leis positivas. Leis naturais não são o produto de instituições humanas.

Não é difícil percebermos que as duas teses são logicamente independentes uma da outra. Poderíamos admitir, pelo menos em princípio, que o conceito de lei, como afirma a tese (i), envolve necessariamente o conceito de justiça, mas negar, por outro lado, que existam quaisquer princípios de justiça passíveis de serem caracterizados em termos de "leis naturais". É claro que, nesse caso, o termo "naturalismo", que aparece na expressão "jusnaturalismo", não seria inteiramente adequado para designarmos uma teoria que afirma simplesmente que o conceito de lei é inseparável do conceito de justiça. Mas a possibilidade de negarmos que haja qualquer lei "natural", de todo modo, não é excluída pela tese (i). Com efeito, autores como, por exemplo, Lon Fuller, Ronald Dworkin, ou Robert Alexy foram ocasionalmente denominados de representantes do jusnaturalismo por se comprometerem com a tese de que algum tipo de idéia moral deve ser pressuposta na elucidação do que é a lei. Mas eles não se comprometem, por outro lado, com a suposição de que idéias morais devam ser compreendidas em termos de a leis "naturais". ${ }^{1}$ A tese (ii), por outro lado, quando formulada independentemente da tese (i), diz apenas que normas morais existem independentemente de instituições humanas. Tais normas seriam, nesse sentido, "naturais". A tese (ii), portanto, não é uma tese que diga respeito a uma concepção específica de direito. A tese (ii) é constitutiva de uma teoria jurídica apenas na medida em que se assume que podemos recorrer a uma determinada lei moral não-positiva para avaliarmos moralmente a lei positiva. ${ }^{2}$

A meu ver, é a tese (i) que constitui o cerne da tradição jusnaturalista. É essa tese, inclusive, o principal foco da crítica dos representantes do positivismo legal ao jusnaturalismo. John Austin, por exemplo, não nega a existência de "leis naturais"; o que ele de fato nega é a existência de uma conexão

\footnotetext{
Brian BIX (1996, p. 231): "Lon Fuller argued against a sharp separation of law and morality, but the position he defended under the rubric of 'natural law theory' was quite different from the traditional natural law theories of Cicero and Aquinas [...]. While the traditional theories were generally taking a particular position on the status of morality (that true moral beliefs are based in or derived from human nature or the natural world, that they are not relative, that they are accessible to human reason, and so on), [...] this second category of 'natural law theories' contains theories specifically about law, which hold that moral evaluation of some sort is required in describing law in general, particular legal systems, or the legal validity of individual laws." Ver também Nicola LACEY (2006, p. 199); Kent GREENWALT (1999, p. 5).

2 Cf. Otfried HÖFFE (1987, p. 99): "Das Naturrecht ist eine überpositive Rechtsidee, von der her das positive Recht als legitim oder illegitim beurteil wird." (Tradução: "O direito natural é uma idéia supra-positiva a partir da qual o direito positivo é avaliado com legítimo ou ilegítimo").
} 
necessária entre o conceito de lei, de um lado, e o conceito de justiça, do outro lado. Como ele afirma em sua principal obra, A Província da Jurisprudência Determinada: "A existência da lei é uma coisa; seu mérito ou demérito, outra coisa. Se ela existe ou não existe, é uma investigação; se ela é conforme ou não a um determinado parâmetro, é uma outra investigação." ${ }^{3}$ De modo similar, Bentham distingüe a "jurisprudência expositória" (expository jurisprudence) da "jurispurdência censorial" (censorial jurisprudence). A primeira teria como tarefa estabelecer o que é o direito (what the law is), ao passo que à segunda caberia investigar como o direito deveria ser (what it ought to be). ${ }^{4}$

Mas que razão pode haver para nos comprometermos com a tese (i), a "tese da inseparabilidade", se ela parece excluir a própria possibilidade de existirem leis injustas? Se o conceito de lei envolve necessariamente o conceito de justiça, então, pelo menos em princípio, uma "lei" injusta não seria realmente uma lei. A tese (i) é claramente formulada, por exemplo, por Tomás de Aquino. Em uma conhecida passagem da Suma Teológica, ele afirma que uma lei injusta seria uma "corrupção da lei" (legis corruptio):

Como diz Agostinho, não parece ser lei aquela que não for justa. Portanto, quanto tem de justiça tanto tem de força de lei. Nas coisas humanas diz-se que algo é justo pelo fato de que é reto segundo a regra da razão. A primeira regra da razão, entretanto, é a lei da natureza (...) Portanto, toda lei humanamente imposta tem tanto de razão de lei quanto deriva da lei da natureza. Se, contudo, em algo discorda da lei natural, já não será lei, mas corrupção da lei [legis corruptio]. ${ }^{5}$

Seria possível interpretarmos essa passagem como se Tomás de Aquino estivesse afirmando que, a rigor, "leis positivas injustas" simplesmente não existissem. Nesse sentido, uma "lei positiva injusta" seria uma espécie de contra-senso, como, por exemplo, a idéia de um triângulo que não fosse formado por três segmentos de reta. Essa interpretação da tese da inseparabilidade, embora seja bastante comum, me parece equivocada, pois ela simplesmente exclui a possibilidade de haver uma lei positiva injusta. Se leis injustas não existissem, deixaria de fazer sentido a pergunta pelas condições que deveriam ser satisfeitas para que uma determinada lei humana (ou lei positiva) pudesse ser considerada justa. Consideramos, por exemplo, que alguns Esta-

\footnotetext{
John AUSTIN (1995, p. 157). Ver também Marcelo ARAUJO (2007b); Norbert HOERSTER (1989; 1997). "...Augustinus dicit in I de Lib. Arb., non videtur esse lex quae justa non fuerit: unde inquantum habet de justitia intatum habet de virtute legis. In rebus autem humanis dicitur esse aliquid justum ex eo quod est rectum secundum regulam rationis. Rationis autem prima regula est lex naturae, ut ex supra dictis patet. Unde omnis lex humanitus posita intantum habet de ratione legis inquantum a lege naturae derivatur. Si vero in aliquo a lege naturali discordet, jam non erit lex, sed legis corruptio." Ver também Q. 92, art. 1: “...a lei tirânica, uma vez que não é segundo a razão, não é lei em sentido absoluto, mas antes uma perversidade da lei." (O texto original é o seguinte: "... lex tyrannica, cum non sit secundum rationem, non est simpliciter lex, sed magis est quaedam perversitas legis.")
} 
dos são injustos, por imporem restrições arbitrárias às liberdades individuais de seus cidadãos. Seria implausível afirmarmos que, no contexto de Estados injustos, não há propriamente um sistema de leis em vigor, mas a mera imposição da força. A possibilidade de reconhecermos algumas leis como injustas depende justamente da possibilidade de, pelo menos em princípio, podermos dissociar conceitualmente a lei das condições que a tornam justa (ou legítima). Dessa forma, se o conceito de lei realmente envolve o conceito de justiça, então é necessário compreendermos a "conexão" que há entre um conceito de lei e o conceito de justiça de uma forma diferente da "conexão" que há entre o conceito de triângulo e o conceito de reta. Com efeito, dizer que o conceito de lei "envolve" o conceito de justiça não pode ser como dizer que o conceito de triângulo "envolve" o conceito de reta, uma vez que essa interpretação acerca do modo como o direito se relaciona com a moralidade torna supérflua a pergunta sobre as condições que devem ser satisfeitas para que uma lei possa ser considerada justa. ${ }^{6}$ Mas não seria possível interpretarmos a tese (i) de uma outra forma? A segunda interpretação da tese (i) que gostaria de examinar poderia ser denominada de "funcional". Ela, por um lado, evita o problema que a primeira interpretação apresenta. Mas, por outro lado, a segunda interpretação, como pretendo mostrar, também é passível de crítica.

Segundo a interpretação funcional, dizer que o conceito de lei "envolve" o conceito de justiça significa simplesmente dizer que é uma função essencial de qualquer lei promover a justiça. ${ }^{7}$ Mas disso não segue que uma lei que não desempenhe de modo adequado a função que lhe é própria deixe de ser, apenas por isso, uma lei. Segundo essa interpretação, uma lei injusta continua sendo uma lei, da mesma forma que, por exemplo, um relógio defeituoso, ainda que sem desempenhar a função que lhe é própria, continua sendo um relógio. No vocabulário de Tomás de Aquino, um relógio defeituoso não teria "razão" de relógio; ele seria uma espécie "corrupção" ou de "perversão" daquilo que realmente esperamos de um relógio. Dessa forma, a tentativa rejeitarmos a tese (i) unicamente com acusação de que ela torna a existência de

\footnotetext{
Cf. por exemplo Neil MACCORMICK (1994, p. 109): "Some natural lawyers flatly deny the existence of an unjust law, but by no means all do; and Finnis has put it beyond denial that the mainstream of the natural law tradition (now flowing bounteously throhgh his own books) affirms the possible existence of such laws, while denying or downgrading their morally compelling quality and on their essential defectiveness as law."

Cf. Gustav RADBRUCH (1946, p. 105): “... wo Gerechtigkeit nicht einmal erstrebt wird, wo die Gleichheit, die den Kern der Gerechtigkeit ausmacht, bei der Setzung positiven Rechts bewußt verleugnet wurde, da ist das Gesetz nicht etwa nur, unrichtiges' Recht, vielmehr entbehrt es überhaupt der Rechtsnatur. Denn man kann Recht, auch positives Recht, gar nicht anders definieren als eine Ordnung uns Satzung, die ihrem Sinne nach bestimmt ist, der Gerechtigkeit zu dienen." (Tradução: "Onde a justiça não é sequer almejada, onde a igualdade, que constitui o cerne da justiça, foi conscientemente negada por ocasião da colocação do direito positivo, nesse caso a lei não é apenas, por assim dizer, direito 'incorreto', mas lhe falta, antes, completamente o caráter de direito. Pois não se pode definir o direito, também o direito positivo, de nenhum outro modo a não ser como uma ordem ou colocação cujo sentido lhe determina servir à justiça"). Cf. ainda Lon FULLER (1967, p. 33-95).
} 
"leis injustas" uma espécie de contradictio in adjecto não me parece justificada. Com efeito, é possível interpretarmos a tese (i) em termos "funcionais": o conceito de lei envolve o conceito de justiça porque, segundo essa interpretação, seria uma função básica de toda lei positiva promover, em maior ou menor medida, alguma concepção de justiça.

No entanto, a interpretação funcional, a meu ver, envolve um problema: não é claro por que deveríamos aceitar que é uma função intrínseca de qualquer lei positiva promover alguma concepção de justiça. Um tirano, por exemplo, poderia criar leis positivas para administrar de modo mais eficiente a exploração das pessoas sob seu poder. A lei seria criada pelo tirano, portanto, com a "função" de garantir a realização de determinados fins. Ao invés de se dirigir a cada um de seus subordinados dando-lhes ordens particulares, o tirano poderia simplesmente estabelecer certos comandos gerais, chamando atenção para as conseqüências negativas que recairiam sobre aqueles que não cumprissem seus comandos gerais. A função desses comandos gerais, portanto, consistiria em tornar mais eficaz, para o tirano, a exploração das pessoas sob seu poder. O fato de a lei positiva, nesse contexto, ser injusta não altera o fato de a lei ter como função específica, não a promoção de uma concepção de justiça, mas, antes, a implementação da vontade daquele que tem o poder de criar leis e de impor sanções àqueles que as descumprem. Em muitos contextos a função da lei positiva é, de um modo ou outro, garantir a realização de uma concepção de justiça. Mas me parece que não há realmente razões para aceitarmos que a função da lei seja sempre a de garantir a consecução desse ideal. A interpretação funcional, portanto, é inaceitável.

Um outro argumento, porém, poderia ser apresentado em favor da tese (i). Esse argumento tenta estabelecer uma conexão necessária entre o direito e a moralidade chamando atenção para a tese segundo a qual apenas leis justas (ou legítimas) seriam capazes de gerar obrigações. Com efeito, a lei que o tirano cria é, de fato uma lei, mas as pessoas sob seu poder parecem não ter realmente a obrigação (ou dever) de obedecer as leis que ele cria. Segundo essa interpretação, portanto, uma lei, no sentido próprio do termo, seria inseparável do conceito de obrigação. Esse argumento, no entanto, como pretendo esclarecer mais adiante, resulta de uma má compreensão da distinção entre frases do tipo "estar obrigado a" e "ter a obrigação de". Mas vejamos, inicialmente, como o defensor da tese (i) poderia procurar estabelecer uma conexão necessária entre o direito e a moralidade através de um esclarecimento do conceito de obrigação.

\section{II}

Uma lei injusta não deixa de ser, apenas por ser injusta, uma lei. Mas podemos sempre nos perguntar que razões temos para, diante de uma lei injusta, agirmos em conformidade com aquilo que é prescrito pela lei. Em algumas circunstâncias, quando somos ameaçados pelo poder da autoridade política 
vigente, por uma questão de sobrevivência, temos uma boa razão para agirmos em conformidade com a lei. Mas a única razão que temos para obedecer a lei, nesses casos, é o medo da punição. Isso ocorre porque a autoridade política vigente, por meio da força de que dispõe, pode nos obrigar à realização de uma ação que, a rigor, não consideramos moralmente correta. A lei, assim, nos obrigaria sem que, de fato, tivéssemos a obrigação de cumprirmos a lei. Dessa forma, um argumento que poderia ser apresentado em favor da tese (i) é que leis injustas, a rigor, não geram obrigações, mas apenas coações. Uma lei somente geraria obrigação se, de alguma forma, ela estivesse associada a alguma idéia moral. Gostaria de esclarecer melhor esse ponto através de um exame da distinção entre "estar obrigado a" e "ter a obrigação de."

Toda lei exige de nós um certo tipo de comportamento. Com outras palavras, as leis nos "obrigam" a fazermos certas coisas ou, conforme o caso, nos obrigam a nos abstermos de fazer algumas coisas. Dessa forma, leis diferem claramente de "conselhos" ou "recomendações", pois a lei não sugere ou recomenda, por exemplo, que paguemos nossos impostos, ela nos obriga a tal. Mas, poderíamos nos perguntar: do fato de estarmos obrigados a cumprir a lei, daí se segue também que tenhamos sempre a obrigação (ou dever) de cumprir a lei? Esse problema pode ser elucidado através de um exame da distinção conceitual entre frases do tipo "S está obrigado a fazer X" e "S tem a obrigação de fazer $\mathrm{x}$ ". Imaginemos que S seja, por exemplo, um gerente de banco em duas situações distintas. Na primeira situação, um assaltante lhe aponta uma arma e diz: "o dinheiro ou a vida!" O gerente está, em virtude das circunstâncias, obrigado a entregar o dinheiro. Estar obrigado, nesse contexto, significa simplesmente estar compelido, forçado ou coagido a fazer alguma coisa. Mas, com relação a essa primeira situação, poderíamos dizer também que o gerente está não apenas obrigado, mas também que ele tem a obrigação de fazer o que se exige dele? Seria certamente estranho que, mais tarde, reportando à polícia o ocorrido, o gerente declarasse que foi obrigado a entregar o dinheiro e que, procedendo desse modo, estaria também cumprindo sua obrigação. O gerente está, de fato, obrigado a entregar o dinheiro, sem, porém, ter a obrigação de fazê-lo. ${ }^{8}$

Consideremos agora, por outro lado, o mesmo gerente em uma segunda situação. O gerente agora se vê obrigado a entregar para um correntista de seu banco a mesma quantia que foi obrigado a entregar ao ladrão da situação anterior. Em certo sentido, o gerente está obrigado da mesma maneira que esteve ao ser assaltado, pois, se agir de modo contrário, sofrerá algum tipo de "conseqüência negativa" - será, por exemplo, demitido. (Podemos mesmo supor que, em algumas circunstâncias, até mesmo as conseqüências negativas não difiram seja no primeiro caso seja no segundo caso. No segundo caso,

Cf. HART (1958, p. 96; 1961, p. 80); KELSEN (1960, p. 45-46); STEMMER (2000, p. 107); GILBERT (2006, p. 30).

A expressão "conseqüência negativa" é usada por Peter STEMMER (2000, p. 121 et passim) 
o gerente poderia, ao invés de ser demitido, ter de pagar uma multa igual à soma que teve de entregar ao assaltante da primeira situação). Mas há agora uma diferença fundamental: o gerente não apenas se vê obrigado, ele tem também a obrigação de agir de uma determinada maneira. E isso é assim porque há uma lei ou regulamento que - ceteris paribus - exige dele a entrega do dinheiro ao correntista, sempre que este o solicitar. Dessa forma, podemos fazer uma distinção conceitual entre o mero estar obrigado a fazer $\mathrm{x}$, de um lado, e a obrigação de fazer x, do outro. Mas quando é que o simples estar obrigado se torna uma obrigação? O que nos permite passarmos de frases do tipo "S está obrigado a fazer X" para frases do tipo "S tem a obrigação de fazer $\mathrm{X}^{\prime \prime}$ ?

Para o jusnaturalismo, toda lei, no sentido próprio do termo, envolveria não apenas um "estar obrigado a", mas também uma "obrigação". A razão pela qual as teses (i) e (ii) foram freqüentemente confundidas, na tentativa de se caracterizar o cerne da tradição jusnaturalista, é que ao mesmo tempo em que se assumiu que uma lei somente geraria uma obrigação - por oposição à mera coação - se ela for legítima, assumiu-se também que os padrões morais por meios dos quais examinamos a legitimidade de uma lei positiva diriam respeito a leis não-positivas, i.e. a leis naturais. Mas existem razões para aceitarmos a existência de tais padrões? Se tais padrões não existirem, então a tese (ii) é falsa. Mas a falsidade da tese (ii) não implica na falsidade da tese (i). Mesmo que admitamos que todas as normas - inclusive as normas morais por meio das quais avaliamos as leis positivas - sejam criações humanas, poderíamos ainda nos perguntar se a tese (i) também é falsa. Gostaria de examinar a seguir o que, a meu ver, seriam os melhores argumentos em favor da tese (ii). Como pretendo mostrar, nenhum desses argumentos é satisfatório. Em seguida, contra a tese (i), pretendo deixar claro que a simples constatação de que uma lei somente pode gerar obrigação se ela for legítima (ou justa) não é, por si só, uma prova de que haja uma conexão necessária entre o conceito de lei e o conceito de justiça. Com efeito, é contingente o fato de algumas leis gerarem obrigações para os indivíduos que estão a elas subordinados, muito embora todas as leis obriguem os indivíduos a elas subordinados à realização (ou, conforme o caso, à omissão) de uma determinada ação.

\section{III}

Leis positivas injustas, a rigor, não geram obrigações, muito embora, em algumas circunstâncias, elas possam perfeitamente nos obrigar à realização de uma determinada ação - como no caso das leis de um tirano. A obrigação que temos de realizar uma determinada ação x, assim, não pode ser explicada unicamente em função da existência das sanções, instituídas por quem tem o poder de sancionar, para o caso da não-realização de x. A obrigação depende, antes, do fato de a lei positiva ser conforme a alguma norma moral. Com outras palavras, punições ou sanções, instituídas socialmente, podem funcionar 
como uma espécie de estímulo para cumprirmos nossas obrigações, mas elas não seriam constitutivas das próprias obrigações. Se esse tipos de punições fossem realmente constitutivas da obrigação que temos de obedecer a lei positiva, então deixaríamos de ter tais e tais obrigações sempre que, agindo em segredo (sem o testemunho de outras pessoas), pudéssemos estar certos de que não seremos punidos. O problema do agir em segredo foi bastante discutido já no contexto da Antigüidade. Foi a tentativa de dar uma resposta satisfatória ao problema do agir em segredo que, a meu ver, levou vários autores, ao longo da tradição do pensamento jusnaturalista, a postular a existência de entidades como "leis naturais".

Há basicamente dois tipos de argumentos que buscam dar conta do problema do agir em segredo. Ambos argumentos envolvem a suposição de que as razões que temos para obedecer as leis são, em última instância, razões morais. A diferença entre os dois argumentos consiste no papel que o conceito de sanção desempenha em cada um deles. (1) O primeiro argumento chama atenção para um tipo de sanção que, por oposição às sanções instituídas socialmente, recairia sobre o transgressor da lei natural independentemente da existência do testemunho de outras pessoas. Ainda com relação ao primeiro argumento, é possível identificarmos dois tipos de sanções não-positivas: (1.1) sanções externas e (1.2) sanções internas. Sanções externas não-positivas seriam aquelas impostas ou por Deus, ou pela própria natureza. Sanções internas, por outro lado, diriam respeito a certas reações afetivas tais como, por exemplo, o sentimento desagradável de remorso, vergonha, indignação, ou má-consciência, de que um indivíduo seria "naturalmente" acometido ao violar uma norma moral. Para o jusnaturalismo, um indivíduo que, ao transgredir uma norma moral, não fosse acometido de tais reações afetivas, realizaria a "natureza humana" de modo menos adequado que outros indivíduos. Seria, inclusive, essa a razão pela qual nos referimos a pessoas desse tipo, incapazes de demonstrar certos tipos de reações afetivas em situações moralmente relevantes, como "desumanas". (2) O segundo tipo de argumento simplesmente desvincula o conceito de obrigação do conceito de sanção. A existência da obrigação, nesse caso, se imporia sobre o indivíduo como uma espécie de imperativo da razão, sem que o indivíduo estivesse propriamente submetido a algum tipo de conseqüência negativa ao descumprir sua obrigação. O fato de estar agindo irracionalmente, por si só, não representaria para esse indivíduo uma conseqüência negativa. Uma terceira solução para o problema do agir em segredo consistiria em chamar atenção para a sombra da dúvida: jamais podemos estar inteiramente certos de que não estamos sendo de fato observados. Essa abordagem do problema do agir em segredo foi proposta, por exemplo, por Epicuro na Antigüidade. ${ }^{10}$ Contudo, não pretendo discutir aqui a abor-

EPICURO (2003, p. 251 / Kyriai doxai 35): "Não pode ocorrer de aquele, que secretamente viola o acordo de não agredir e de não ser agredido, possa ter confiança de que permanecerá nãodescoberto, mesmo se ele, no momento, permanece mil vezes não-descoberto. Com efeito, até sua 
dagem oferecida por Epicuro, pois ela reconduz a razão que temos para obedecermos a lei positiva, mesmo quando estamos agindo supostamente em segredo, às penalidades instituídas socialmente. O que me interessa aqui é examinar os argumentos que procuram justamente dissociar a razão para obedecermos a lei das penalidades instituídas socialmente, caso a lei seja descumprida.

Gostaria de expor agora os argumentos (1.1), (1.2) e (2), com um pouco mais de precisão, referindo-me a quatro autores na tradição do pensamento filosófico que se comprometeram, de um modo ou outro, com esses argumentos, a saber: (1.1) Antiphon, (1.2) J. S. Mill, e (2) Kant e Wittgenstein. Esses autores, contudo, não são tradicionalmente vistos como representantes emblemáticos do jusnaturalismo. A referência que faço a eles aqui tem como objetivo, antes, chamar atenção para diferentes tipos de respostas que podem ser dadas à pergunta sobre a fonte de nossas obrigações.

O primeiro tipo de argumento (1.1) chama atenção para a existência de sanções divinas ou naturais. A idéia segundo a qual Deus puniria a realização de ações injustas, mesmo quando tais ações fossem realizadas em segredo, é indissociável de uma concepção teológica ou religiosa de mundo. ${ }^{11}$ Sanções "naturais", por outro lado, poderiam, pelo menos aparentemente, ser explicadas sem recorrermos a uma concepção teológica ou religiosa de mundo. No contexto da Antiguidade, Antiphon, por exemplo, se comprometeu claramente com essa versão do argumento (1.1). Para Antiphon continuamos submetidos a uma punição mesmo quando não estamos sendo observados, pois existem sanções que se fazem exercer independentemente do testemunho de outras pessoas. Essas sanções, assim, seriam impostas, como ele afirma, pela própria natureza:

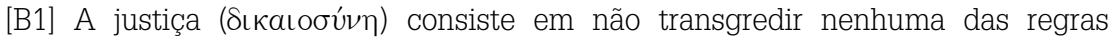
( $\nu$ ó ı $\mu \alpha)$ do Estado em que se vive como um cidadão. Assim uma pessoa faria uso da justiça do modo mais vantajoso para si própria se, na presença de testemunhas, ela tivesse as leis (vónous) na mais alta estima; mas, na ausência de testemunhas, ela tomasse em alta conta as exigências da natureza ( $\phi \dot{\sigma} \sigma \omega s)$. Pois as exigências das leis são invenções, enquanto as exigências da natureza são necessárias; e as exigências das leis são por contrato, e não por natureza, enquanto as exigências da natureza são naturais, e não por acordo. [B2] Assim, alguém que transgride as leis está livre de vergonha e punição, se não for visto pelos participantes do contrato, mas, se for visto, não. Por outro lado, se alguém tenta violar uma das exigências inerentes à natureza - o que é impossível - o prejuízo que se sofre não é menor se não for observado por ninguém, e não é maior se for obser-

morte é incerto se ele ainda permanecerá não-descoberto." Cf. também EPICURO (2003, p. 257 / Gnomologium Vaticanum, 7): "É difícil permanecer não-descoberto quando se comete uma injustiça. Ter a certeza de que se permacerá não-descoberto, impossível." Ver também STEMMER (2002, p. 169).

11 Cf. por exemplo Novo Testamento, Mat., 6:4, 18; Heb. 4:13. 
vado por todos, pois se é prejudicado, não por força da opinião ( $\delta$ ́́łav) das pessoas, mas em verdade $(a ̉ \lambda \eta ́ \theta \in \iota \alpha \nu){ }^{12}$

O argumento (1.2) chama atenção, por outro lado, para a existência de sanções internas ao próprio indivíduo, o que significa que continuaríamos tendo razões para agir de um determinado modo, mesmo quando não estivéssemos sendo observados. Um autor que se comprometeu claramente com o argumento (1.2) foi, por exemplo, Mill. Para Mill, existem sanções relacionadas à própria "consciência" do indivíduo. No quinto capítulo de Utilitarismo, Mill afirma o seguinte:

[...] a idéia de uma sanção penal, que é a essência do direito [law], entra não apenas na concepção de injustiça, mas também na de qualquer tipo de coisa errada [wrong]. Não denominamos uma coisa como errada ao menos que queiramos dizer que a pessoa deveria ser punida de algum modo ou outro por fazer isso; se não pelo direito, pela opinião de seus semelhantes; se não pela opinião, pelas reprovações de sua consciência. Este parece ser o ponto central da distinção entre moralidade e simples a expediência. Trata-se de uma parte da noção de Dever, em cada uma de suas formas, que uma pessoa possa ser corretamente [rightfully] compelida a realizá-lo. ${ }^{13}$

Com relação ao argumento (2), o que desvincula o conceito de obrigação do conceito de sanção, ele tem em Kant seu principal representante. Kant procura mostrar que seria mesmo uma constatação do senso comum a idéia segundo a qual uma obrigação (ou dever) moral implicaria em uma "necessidade absoluta", independentemente de quaisquer recompensas ou penalidades a que pudéssemos estar submetidos. Como ele afirma no prefácio da Fundamentação da Metafísica dos Costumes: "Oualquer um deve conceder que uma lei, para ser moral, isto é, para ser fundamento de uma obrigação, precisa implicar em uma necessidade absoluta..." ${ }^{\prime 4}$ Uma posição similar é defendida também por Wittgenstein. Em uma passagem de seu diário, datada de 30 de julho de 1916, Wittgenstein afirma o seguinte:

"O primeiro pensamento no estabelecimento de uma lei moral [ethischen Gesetzes] da forma 'Tu deves...[Du sollst]' é: “e se eu não fizer isso?' É claro que a ética

12 Antiphon, Sobre a Verdade, frag. 44 B (final do séc. 5 a.C.), apud Michael GAGARIN (2002, p. 67). Ver também PLATÃO (República, 359b-360d), onde Platão discute o mito do "anel de Gyges".

13 MILL (1998, p. 93). O texto original é o seguinte: “...the idea of penal sanction, which is the essence of law, enters not only into the conception of injustice, but into that of any kind of wrong. We do not call anything wrong, unless we mean to imply that a person ought to be punished in some way or other for doing it; if not by law, by the opinion of his fellow-creatures; if not by opinion, by the reproaches of his own conscience. This seems the real turning point of the distinction between morality and simple expediency. It is a part of the notion of Duty in every one of its forms, that a person may rightfully be compelled to fulfil it."

14 KANT (1984, p. 22). O texto original é o seguinte: "Jedermann muß eingestehen, daß ein Gesetz, wenn es moralisch ist, d.i. als Grund einer Verbindlichkeit, gelten soll, absolute Notwendigkeit bei sich führen müsse..." 
nada tem a ver com penalidade ou recompensa. Portanto, essa questão sobre as conseqüências de uma ação deve ser irrelevante." ${ }^{15}$

Dessa forma, uma obrigação (por oposição à mera coação) continuaria existindo, mesmo quando não estamos sendo observados, porque: (argumento 1.1) Deus, ou a própria natureza, podem nos punir; ou porque (argumento 1.2) a "consciência" gera para o transgressor da norma moral uma espécie de punição; ou ainda porque (argumento 2) a obrigação é, como um imperativo da razão, em si mesma inteiramente independente de qualquer tipo de punição ou conseqüência negativa.

Para o jusnaturalista, portanto, dizer que o conceito de lei envolve o conceito de justiça significa dizer que "leis injustas", ainda que coercitivas, a rigor não geram obrigações. Elas não geram obrigações porque a vontade do legislador, nesse caso, entra em conflito com a vontade de Deus, ou com uma ordem natural; ou porque a vontade do legislador contraria certas disposições morais inerentes à natureza humana; ou ainda, porque ela é incompatível com o que a razão realmente exige de nós, independentemente de quaisquer disposições ou inclinações que possamos ter. Esse argumento é diferente daquele argumento que tenta estabelecer a inseparabilidade do direito e da moral apelando para a suposição de que seria uma função implícita de toda lei promover alguma concepção de justiça. Esse ponto pode ser elucidado um pouco melhor se retornarmos agora ao exemplo do gerente de banco, mencionado anteriormente. Consideremos agora o gerente em uma terceira situação. (Na primeira situação ele entregou o dinheiro a uma pessoa para não ser alvejado por um assaltante; na segunda, para não ser demitido. Vimos que apenas no segundo caso era sua obrigação entregar o dinheiro, muito embora estivesse a isso obrigado em ambos os casos). Nessa terceira situação, o gerente constatou que, por um erro no sistema, sobrou uma determinada soma em dinheiro em um dos caixas. Ele sabe, com toda certeza, que "pode" (no sentido de "estar em condição de") se apropriar do dinheiro sem sofrer qualquer conseqüência negativa. Ele não está sendo obrigado (coagido, forçado, compelido, etc.) a devolver o dinheiro, pois sabe que, por não estar sendo observado, não está sujeito a qualquer conseqüência negativa socialmente instituída. Mas podemos nos perguntar se ele tem, ainda assim, a obrigação de devolver o dinheiro. Para o jusnaturalista, nesse caso, a despeito da ausência de coação,

\footnotetext{
WITTGENSTEIN (1963, p. 171). O texto original é o seguinte: "Der erste Gedanke bei der Aufstellung eines ethischen Gesetzes von der Form 'du sollst ...' ist: 'Und was dann, wenn ich es nicht tue?' Es ist klar, dass die Ethik nichts mit Strafe und Lohn zu tun hat. Also muss diese Frage nach den Folgen einer Handlung belanglos sein." Wittgenstein permaneceu fiel a uma concepção kantiana de obrigação até pelo menos 1929, como sugere o texto da conferência que proferiu em Cambridge nesse ano (WITTGENSTEIN 1965, p. 5). Ainda em 1929, Wittgenstein faz também a seguinte observação em uma de suas notas: "Wenn etwas gut ist, so ist es auch göttlich. Damit ist seltsamerweise meine Ethik zusammengefasst." (WITTGENSTEIN 1994, p. 24 / MS 107 196). (Tradução: "Se algo é bom, então ele é também divino. Dessa forma, minha ética é estranhamente resumida.").
} 
há, ainda assim, a obrigação de obedecermos a lei. E isso é assim porque essa lei é inteiramente conforme a princípios que não foram estabelecidos por força de circunstâncias sociais específicas. Tais princípios poderiam ser considerados como a expressão de uma lei natural. Nesse terceiro caso, portanto, não poderíamos dizer ao gerente: "tu deves cumprir a lei (devolver o dinheiro), pois, do contrário, serás demitido". A justificativa para a obrigação de devolver o dinheiro tem de levar em consideração o fato de a pessoa em questão estar agindo em segredo, o que a possibilita escapar desse tipo de conseqüência negativa (ser demitida). Dessa forma, os seguintes argumentos poderiam ser apresentados:

ARGUMENTO (1.1): “Tu deves devolver o dinheiro, pois, do contrário, serás punido por algum tipo de instância não-positiva (por Deus, ou pela própria natureza)."

ARGUMENTO (1.2): "Tu deves devolver o dinheiro, pois, do contrário, serás punido pela sua própria consciência. E se tua própria consciência não gera uma razão para devolveres o dinheiro, isso é um indício de que és, de certa forma, desumano."

ARGUMENTO (2): "Tu deves devolver o dinheiro, pois é isso que a razão exige de ti, independentemente de qualquer tipo de penalidade a que possas estar submetido. Não devolver o dinheiro seria uma forma de irracionalidade".

As idéias morais a que se recorre aqui, pelo menos em princípio, parecem não ser o produto de instituições humanas. Elas seriam, como afirma a tese (ii), de alguma forma "naturais". Se isto é assim, então a obrigação de obedecermos a lei se justificaria, não pelo fato de ela envolver a ameaça de uma sanção, compreendida em termos de conseqüências negativas instituídas socialmente. A obrigação de obedecermos a lei se justificaria, antes, através de um dos argumentos (1.1), (1.2), ou (2), expostos acima. A diversidade de posições na tradição do pensamento jusnaturalista se explica justamente pela diversidade de concepções de obrigação moral a que podemos recorrer na tentativa de darmos uma resposta às razões últimas que temos para obedecer a lei. Os argumentos (1.1), (1.2), e (2) representam ao mesmo tempo uma defesa da tese (i) e da tese (ii). Trata-se de uma defesa da tese (i) porque há aqui tentativa de se dissociar a força vinculatória da lei positiva do poder ou autoridade de quem criou a lei positiva. Uma lei positiva teria força vinculatória, não pelo fato de ser respaldada por uma sanção positiva, mas, antes, pelo fato de estar em consonância com algum tipo de idéia moral. Trata-se também de uma defesa da tese (ii) porque esses argumentos envolvem ainda a suposição de que as idéias morais em questão aqui não dizem respeito a circunstâncias sociais determinadas. Essas idéias morais seriam, de alguma maneira, "naturais"; elas seriam, com outras palavras, independentes da existência de instituições humanas. Mas devemos nos perguntar agora se essa defesa da tese (i) e da tese (ii) é satisfatória. 
O argumento (1.1) é implausível, pois envolve a premissa teológica segundo a qual Deus nos dá a lei. Com efeito, sem nos comprometermos com idéias religiosas ou teológicas, não há realmente nenhuma razão para assumirmos que Deus existe e que ele nos impõe certas normas. Já na Antigüidade foi levantada a questão sobre se a idéia de punições divinas não seria, na verdade, uma invenção humana, utilizada para demover os indivíduos da tentação de desobedecer as leis quando não estivessem sendo observados. ${ }^{16} \mathrm{Na}$ versão aparentemente não-teológica de Antiphon não é claro de que modo a punição seria imposta pela natureza. Como Bentham percebeu, na tradição do pensamento jusnaturalista a palavra "natureza" funciona freqüentemente apenas como um substituto para a palavra "Deus". ${ }^{17}$ O argumento (2), por outro lado, não é menos implausível, pois não é claro o que significa dizer que "devemos" fazer x, sem especificarmos o que acontecerá no caso da não-realização de x. Wittgenstein se deu conta do equívoco aqui e se distanciou mais tarde da posição kantiana que defendera anteriormente. Como ele afirma em um depoimento da década de trinta:

O que significa a palavra 'deve' [soll]? Uma criança deve fazer isso significa: se ela não o fizer, então isso ou aquilo de desagradável correrá. Recompensa e punição. O essencial nisso é: o outro é movido a fazer alguma coisa. Um deve [Soll] portanto somente tem sentido, se houver algo por de trás do deve, algo que lhe dê força [Nachdruck], um poder [Macht] de punir ou recompensar. Um deve [Soll] em si mesmo é completamente desprovido de sentido [unsinnig]. ${ }^{18}$

O argumento (1.2): "Tu deves cumprir a lei, pois, do contrário, serás punido pela sua própria consciência", parece, pelo menos em princípio, menos problemático. Ele tenta estabelecer uma razão para agirmos de uma determinada maneira chamando atenção para a existência, em nós, de certas "disposições morais". A presença de uma disposição moral gera para o indivíduo uma razão para agir, pois é a presença dessa disposição que, nas situações relevantes, desperta no indivíduo tais e tais reações afetivas desagradáveis tais

${ }^{16}$ Cf. fragmento de Sisyphus (DK 88B.25) de autoria provável de Crítias (460-403 a.C.): "Havia um tempo em que a vida dos seres humanos era desordenada / como a vida dos animais selvagens, e a vida era governada pela força / e não havia recompensa para os bons / nem punição para os maus.

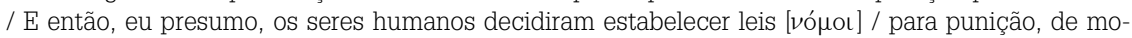
do que a justiça pudesse regrar / e deter a violência. / E eles puniam qualquer um que cometesse um crime. / Então as leis os impediam de cometer atos públicos de violência. / Mas eles continuaram fazendo isso em segredo, então foi que, como acredito, um homem astuto e inteligente / inventou para os mortais o medo dos deuses de modo que / pudesse haver algo que detivesse os maus, mesmo se / eles estivessem agindo em segredo..." Para uma tradução e análise desse fragmento, ver Charles KAHN (1997).

17 BENTHAM (1987, p. 54-55): "What is the source of these imprescritible rights - these unrepealable rights? [...] Made by what? Not by a God - they allow of none; but by their goddess, Nature."

18 WITTGENSTEIN (1984, p. 118). O texto original é o seguinte: "Was heißt das Wort 'soll'? Ein Kind soll das tun, heißt: wenn es das nicht tut, dann wird das und das Unangenehme eintreten. Lohn und Strafe. Das Wesentliche daran ist: der andere wird bewogen, etwas zu tun. Ein Soll hat also nur Sinn, wenn hinter dem Soll etwas steht, das ihm Nachdruck gibt - eine Macht, die straft und belohnt. Ein Soll an sich ist unsinnig". 
como remorso, má-consciência, vergonha, etc. O que torna esse argumento atrativo para o defensor do jusnaturalismo é a suposição de que uma disposição moral não poderia ser criada da mesma forma como criamos leis e sanções positivas. De fato, é possível supormos que indivíduos possam chegar a um acordo sobre que penalidades serão impostas àqueles que transgredirem tais e tais leis positivas. Mas seria estranho que indivíduos pudessem, da mesma forma, determinar que os transgressores de tais e tais normas serão acometidos de um profundo sentimento de remorso, indignação, ou má-consciência. Reações afetivas desse tipo não surgem diretamente de acordos ou de imposições. Elas parecem surgir, de certo modo, "naturalmente". Assim, a tese (ii), quando defendida com base no argumento (1.2), não depende necessariamente de premissas teológicas, muito embora vários autores na tradição do pensamento jusnaturalista tenham se comprometido com tais idéias. Ela é também independente da suposição de que existiria um tipo de dever categórico, i.e. um tipo de dever que nos vincularia à realização (ou omissão) de uma determinada ação, por força de uma "necessidade absoluta", independentemente, portanto, de quaisquer conseqüências negativas decorrentes da não realização desta ação. Dessa forma, a tese (ii) poderia ser defendida simplesmente com base na constatação de que existem algumas "sanções internas", decorrentes de certas disposições morais que nos seriam inatas. Essas sanções internas representariam para o indivíduo uma justificativa para a obrigação de obedecer a lei positiva mesmo naquelas ocasiões em que ele não estivesse sendo observado por outras pessoas.

Contudo, poderíamos nos perguntar agora se essa defesa da tese (ii) é realmente sustentável. Com efeito, a seguinte objeção poderia ser formulada. Fenômenos como "má-consciência", "indignação", "remorso", etc. resultam, na verdade, de um gradual processo de socialização e da introjeção do modus vivendi de uma comunidade específica. Se esses tipos de reações afetivas, diferentemente das leis positivas, não surgem por força de acordos ou de imposições, daí não se segue, porém, que fenômenos desse tipo surjam "naturalmente", independentemente de circunstâncias sociais específicas, como se fossem parte de nossa própria natureza. Segundo essa objeção, portanto, todas as leis, bem como todas as obrigações, seriam, em última instância, o produto de instituições humanas. Essa objeção constitui, a meu ver, uma importante dificuldade para a tese (ii). Quando experimentamos reações afetivas como "indignação", "remorso" ou "má consciência", somos tentados a ver nessas reações a expressão da própria "natureza humana". Mas, como a objeção sugere, seria um engano, do fato de não podermos atribuir a origem desses sentimentos diretamente à vontade do legislador, ou aos termos de um contrato, concluirmos que tais sentimentos seriam a manifestação de um tipo de normatividade que não decorreria, ela própria, de circunstâncias sociais específicas.

No entanto, um defensor da tese (ii) poderia alegar o seguinte contra essa objeção: é bem possível que jamais viéssemos a experimentar sentimentos 
como "indignação", "remorso" ou "má-consciência", se não tivéssemos passado por um gradual processo de socialização, mas podemos sempre nos perguntar por que, afinal, somos socializados de modo a, em tais e tais situações, reagirmos afetivamente com tais e tais disposições morais. Para o defensor da tese (ii), assim, a objeção formulada acima não seria ainda uma objeção definitiva à tese de que haveria um âmbito "natural" de normatividade, pois seria possível alegar que somente socializamos os indivíduos de um determinado modo, introjetando neles, por meio de instituições diversas, tais e tais sentimentos morais, porque, de alguma maneira, "reconhecemos" que certos arranjos sociais são injustos. Se reações afetivas como má-consciência, indignação, ou remorso são o resultado de um processo de socialização, a existência do próprio processo de socialização, por sua vez, se justificaria a partir da constatação de que é assim que introjetamos nos indivíduos uma disposição para cumprir as normas ou leis que "reconhecemos" como justas. Nesse sentido, o defensor do jusnaturalismo poderia mesmo sugerir a seguinte analogia: foi apenas no contexto da cultura científica dos séculos 17 e 18 que Isaac Newton descobriu certas leis que descrevem o movimento dos planetas; da mesma forma, foi apenas no contexto da cultura filosófica e política dos séculos 17 e 18 que entidades normativas como "direitos naturais" ou "direitos humanos" foram descobertas e passaram, desde então, a figurar em nosso vocabulário jurídico, político, e moral. Mas, assim como a teoria da gravitação universal seria verdadeira, independentemente da cultura científica no contexto da qual ela foi descoberta, seres humanos seriam sujeitos de direitos humanos (ou direitos naturais), independentemente das circunstâncias políticas e sociais no contexto das quais tais idéias começaram a ser discutidas. O que está aqui em questão é a suposição de que, assim como estrelas e planetas, leis e direitos "naturais" teriam uma realidade própria, independentemente da existência de instituições humanas. Dessa forma, para o jusnaturalismo, seria possível "reconhecermos" certas leis "naturais" graças a um tipo de "faculdade moral" análoga à faculdade cognitiva por meio da qual descrevemos as leis do mundo natural. Essa analogia entre o modo como adquirimos conhecimento do mundo físico e o modo como adquirimos conhecimento dos princípios da moralidade é claramente defendida, por exemplo, por Kant. No prefácio da Fundamentação Metafísica dos Costumes, Kant afirma que tanto a física quanto a ética são tipos de investigações sobre "leis" (Gesetze). ${ }^{19}$ A mesma analogia é

19 KANT (1984, p. 19). Kant pode ser considerado como um representante do jusnaturalismo porque ele, em certo sentido, aceita a tese (ii): ele assume que existem normas morais que não foram simplesmente criadas por seres humanos. A existência dessas normas é independente da existência de instituições humanas. É bem verdade, porém, que, para Kant, não é nem a natureza nem Deus que impõem aos homens essas normas. Elas se imporiam, antes, como um imperativo da razão para qualquer ser racional. Se essa ressalva é suficiente para desqualificar Kant como um representante do tipo de jusnaturalismo que se compromete com a "tese metafísica", essa é uma questão que não pretendo examinar aqui. Por outro lado, na medida em que Kant nega a "tese da inseparabilidade", ele pode ser visto como um representante do positivismo legal. Para uma discussão sobre a posição 
defendida também por outros filósofos do século 18. Thomas Reid, por exemplo, afirma o seguinte:

Os primeiros princípios da moralidade são os ditames imediatos da faculdade moral. Eles nos mostram, não o que o homem é, mas o que ele deve ser. O que quer que seja percebido imediatamente como justo, honesto, ou honrável, na conduta humana, carrega consigo obrigação moral, e o contrário carrega demérito e reprovação; e, dessas obrigações morais que são percebidas imediatamente, todas as outras obrigações morais devem ser deduzidas. Aquele que julga sobre a cor de um objeto deve consultar os seus olhos, em boas condições de iluminação. [...] De modo análogo, aquele que julga sobre os primeiros princípios da moralidade, deve consultar sua consciência, ou faculdade moral, quando se está calmo e tranqüilo, não comprometido por interesse, afeto, ou costume. ${ }^{20}$

Essa analogia, no entanto, é problemática e desnecessária. Ela é problemática porque envolve a suposição de que teríamos uma faculdade de descobrir ou "reconhecer" os princípios da moralidade, análoga à faculdade (ou faculdades) por meio da qual conhecemos os objetos do mundo físico. Mas existem realmente razões para aceitarmos essa suposição? Temos realmente uma faculdade, por assim dizer, de percebermos fatos morais? Essa analogia é também desnecessária, pois podemos explicar a existência de princípio morais, bem como a racionalidade de nossas disposições morais, da mesma forma como explicamos a existência de leis positivas, a saber: como um tipo de criação humana. A tese que defendo aqui, portanto, é que podemos "criar" disposições morais da mesma forma como criamos leis positivas. Mas essa tese é plausível? A primeira objeção que se poderia formular contra ela é a seguinte: leis positivas podem ser criadas seja pela imposição de quem tem o poder de criar e impor sanções, seja através de um acordo mútuo entre indivíduos que se auto-impõem as leis. Mas seria possível impormos a outros indivíduos certas disposições morais? Seria possível, por força de um acordo, "escolhermos" sermos movidos por uma disposição moral como, por exemplo, um senso de justiça? A seguir, pretendo elucidar em que sentido é plausível fa-

de Kant na tradição do positivismo legal, bem como na tradição do jusnaturalismo, ver WALDRON (2003) e Leonard KRIEGER (1965).

${ }^{20}$ Thomas REID (1983, p. 322-323). O texto original é o seguinte: "The first principles of morals are the immediate dictates of the moral faculty. They shew us, not what man is, but what he ought to be. Whatever is immediately perceived to be just, honest, and honourable, in human conduct, carries moral obligation along with it, and the contrary carries demerit and blame; and, from those moral obligations that are immediately perceived, all other moral obligations must be deduced. He that will judge of the colour of an object, must consult his eyes, in good light [...] In like manner, he that will judge of the first principles of morals, must consult his conscience, or moral faculty, when he is calm and dispassionate, unbiased by interest, affection, or fashion." Cf. Tomás de AQUINO (Summa Teologiae, IIII, Q. 94, art. 2): "Dicendum quod, sicut supra dictum est, praecepta legis naturae hoc modo se habent ad rationem practicam sicut principia prima demonstrationum se habent ad rationem speculativam: utraque enim sunt quaedam principia per se nota." (Tradução: "Como acima foi dito, os preceitos da lei da natureza se têm em relação à razão prática como os princípios primeiros das demonstrações se têm em relação à razão especulativa: uns e outros são conhecidos por si."). Cf. ainda ibid., Q. 91, art. 3. 
larmos de uma "escolha" por certas disposições morais. Minha intenção é tornar claro, contra a tese (ii), que disposições morais não precisam ser compreendidas como inerentes à natureza humana. O argumento que pretendo defender recorre a algumas idéias centrais da teoria moral contratualista, tal como ela é defendida, por exemplo, por David Gauthier e Peter Stemmer.

\section{IV}

Não podemos impor a um indivíduo a adoção voluntária de uma disposição moral. Na verdade, não podemos sequer nos impor a nós próprios, por meio de um procedimento decisional direto, a adoção de uma tal disposição. Nesse sentido, é correto dizer que não podemos realmente "escolher" a adoção voluntária de um senso de justiça ou de qualquer outra disposição desse tipo. Mas disso não se segue nem que disposições morais nos sejam inatas, nem que elas nos sejam introjetadas de modo inteiramente passivo ao longo de um gradual processo de socialização. Na verdade, não é claro como poderíamos determinar com precisão a origem de nossas disposições morais. Se elas surgiram em nós unicamente através do condicionamento social, ou por um processo de seleção natural, ou, ainda, se elas são de alguma forma hardwired em nossos cérebros são questões que, embora relevantes, não tratam do aspecto propriamente normativo que o conceito de disposição moral envolve. A determinação da origem de nossas disposições morais, por si só, ainda não elucidaria a questão sobre as razões que temos para agirmos movidos, por exemplo, por um senso de justiça.

A teoria do contrato social moderna percebeu que a questão sobre a origem do Estado é diferente da questão filosófica acerca das razões que podem ser apresentadas para a manutenção da instituição do Estado. Da mesma forma, a teoria moral contratualista não diz respeito a uma discussão sobre como as disposições morais surgiram em nós, i.e. se elas têm sua origem em uma "escolha" ou em qualquer outra instância. Como uma teoria sobre o surgimento das disposições morais a teoria moral contratualista seria, a meu ver, tão pouco interessante quanto uma teoria do contrato social como um tipo de teoria sobre o surgimento do Estado. Nem Hobbes nem a tradição do contrato social posterior a Hobbes se comprometeu com a tese segundo a qual o Estado teria, de fato, surgido a partir de um contrato entre indivíduos interessados na superação do estado de natureza. ${ }^{21}$ Quando começamos a refletir sobre questões políticas já nos encontramos submetidos à autoridade do Estado. A figura do contrato é um artifício metodológico de que dispomos para examinarmos a racionalidade da estrutura política em que estamos de fato inseridos, qualquer que seja sua origem. A racionalidade da estrutura política da comunidade em que vivemos é explicada por apelo à idéia de um contrato na medida em que reconhecemos que "escolheríamos" nos associar a outros indiví-

${ }^{21}$ STEMMER (2004, p. 216-217). 
duos para criarmos o Estado, caso não estivéssemos de fato já inseridos no contexto de uma comunidade política. A constatação de que uma tal "escolha", na verdade, jamais foi de fato realizada não é relevante para a teoria do contrato social. Da mesma forma, ao refletirmos sobre o problema das disposições morais, nós já nos compreendemos como agentes morais, como pessoas genuinamente movidas por um senso de justiça. Mas a questão que podemos nos colocar é se podemos nos reconhecer, de alguma forma, como responsáveis pelas disposições morais que de fato possuímos. Para que possamos nos reconhecer como responsáveis por nossas disposições morais não é necessário que elas tenham, de fato, surgido em nós como resultado de uma "escolha". Ao refletirmos sobre as disposições morais de que somos possuidores, podemos também reconhecer que, independentemente do modo como elas de fato surgiram em nós, é de nosso interesse sermos movidos por tais disposições. Com efeito, seria irracional admitir em um esquema de cooperação para vantagem mútua um indivíduo inteiramente desprovido de tais disposições. Essa tese constitui um dos pontos centrais da teoria moral contratualista.

Para Gauthier, o que caracteriza o agir moral é, antes de mais nada, a adoção de certos princípios de imparcialidade. Mas os princípios de imparcialidade característicos da moralidade não precisam ser concebidos como inatos à natureza humana, ou como passíveis de serem descobertos por uma "faculdade moral". Eles podem ser justificados através de uma investigação sobre o modo como melhor podemos implementar nossos próprios interesses. Como Gauthier afirma já no início de sua principal obra, Morals by Agreement:

Nossa tese é que, em algumas situações envolvendo interação com outros, um indivíduo escolhe racionalmente apenas na medida em que limita a implementação de seu próprio interesse ou vantagem de modo a conformá-los a princípios que expressam a imparcialidade característica da moralidade. ${ }^{22}$

Esse argumento, no entanto, por si só, não elimina o problema do agir em segredo. Se um indivíduo age motivado unicamente pela implementação do auto-interesse, então, nas circunstâncias em que não estiver sendo observado, a escolha racional para ele consistirá em negligenciar os princípios da moralidade. Como vimos anteriormente, é justamente a presença de uma disposição moral no indivíduo a garantia de que ele agirá em consonância com os princípios da moralidade independentemente do testemunho de outras pessoas. Mas como seria possível reintegramos o conceito de disposição moral no quadro conceitual da teoria moral contratualista? Gauthier procura mostrar que, ao percebermos as vantagens decorrentes da adoção dos princípios de imparcialidade que caracterizam o agir moral, perceberíamos também que seria racional "escolhermos" ter uma disposição para agirmos constantemente em

22 GAUTHIER (1986, p. 4). Ver também GAUTHIER (2003, p. 162): "A idéia moral fundamental, acredito, é de não tomarmos vantagem - de não melhorarmos nossa situação tornando pior a situação dos outros sem o consentimento deles." 
consonância com tais princípios. Para Gauthier, a escolha racional não diz respeito à escolha por esta ou aquela ação, tomada isoladamente; ela diz respeito, antes, à escolha por um tipo de disposição moral em função da qual faremos escolhas futuras. Esse ponto é formulado por Gauthier, por exemplo, na seguinte passagem:

Uma escolha é racional se, e somente se, ela maximiza a utilidade esperada pelo agente. Identificamos racionalidade com maximização da utilidade ao nível da escolha por disposições. Uma disposição é racional se, e somente se, o agente que a possui pode esperar que suas escolhas the rendam não menos utilidade do que as escolhas que ele faria se ele possuísse qualquer disposição alternativa. ${ }^{23}$

Ao "internalizarmos" certas disposições morais tais como, por exemplo, "honestidade" ou um "senso de justiça", que são disposições características dos indivíduos que respeitam os princípios de imparcialidade típicos da moralidade, nós nos mostraríamos como parceiros confiáveis no âmbito das relações sociais. ${ }^{24}$ Com efeito, se, em todas as situações, nos propuséssemos a refletir sobre quais decisões contribuiriam de modo mais eficaz para realização de nosso próprio interesse, tendo em vista unicamente as situações tomadas isoladamente, terminaríamos por nos mostrar como egoístas e, portanto, como parceiros pouco confiáveis para a cooperação social. Dessa forma, ao nos mostrarmos como egoístas, deixaríamos de nos beneficiar das vantagens da cooperação social, que são desfrutadas por aquelas pessoas que não procuram, a cada instante, ponderar sobre qual curso de ação melhor contribuirá para a implementação de seus interesses mais imediatos. ${ }^{25}$ Como Gauthier afirma:

Apenas a pessoa verdadeiramente disposta para a honestidade e justiça pode esperar auferir seus benefícios, pois apenas uma tal pessoa pode ser racionalmente admitida naqueles arranjos para benefício mútuo - sejam arranjos de fato ou práticas assentidas implicitamente - que se baseiam em honestidade e justiça, em participação voluntária. ${ }^{26}$

23 GAUTHIER (1986, p. 182-183). Ver também STEMMER (2000, p. 162-191) para uma análise da relação entre disposições morais e o problema do agir em segredo a partir de uma perspectiva contratualista.

${ }^{24}$ Cf. GAUHTIER (1986, p. 156): "A pessoa justa é apta para a sociedade porque ela internalizou a idéia do benefício mútuo, de modo que, ao escolher seu curso de ações, ela considera primordialmente a perspectiva da realização da conseqüência co-operativa."

25 Cf. GAUTHIER (1986, p. 162): "Uma pessoa disposta a violar seus acordos não pode ser admitida como um parceiro para empreendimentos co-operativos por aqueles que são racionais e conscientes de sua disposição; e, assim, uma tal pessoa não pode esperar racionalmente colher os benefícios disponíveis para os co-operadores. Mesmo se ocasionais quebras de acordo lhe beneficiassem, ainda assim a disposição que a leva a tais quebras não a beneficiaria." Cf. também Marcelo de ARAUJO (2007a, p. 68-69).

26 GAUTHIER (1986, p. 182). Ver também GAUTHIER (1993, p. 195-96): "A person who lacks a sense of justice will have no internal brake to stop him taking advantage of his fellows' compliance with the constraints of cooperation while ignoring those constraints himself whenever he finds it possible and profitable to do so." [...] "However, possession of a sense of justice may nevertheless be greatly to one's advantage even in realizing one's nonmoral concerns, because it contributes to 
Mas o que significa dizer que, por força de uma "escolha" racional, podemos decidir nos tornarmos uma pessoa movida, por exemplo, por um senso de justiça? É realmente possível fazermos uma tal "escolha"? Gauthier, na verdade, não esclarece de modo adequado esse ponto. ${ }^{27}$ Por outro lado, a meu ver, é possível, ainda assim, compreendermos a racionalidade de nossas disposições morais sem abandonarmos o quadro conceitual da teoria moral contratualista. Mesmo admitindo que não podemos simplesmente nos decidir nos tornarmos uma pessoa movida por tais e tais disposições morais, seria de nosso interesse contribuir para criação e manutenção de instituições que estimulassem os demais indivíduos com os quais interagirmos a agirem motivados por um senso de justiça. Isso significa que, se de fato não escolhemos ter as disposições morais que temos, reconhecemos, ainda assim, que é de nosso interesse criar e manter as instituições que podem contribuir para fomentar nos outros indivíduos a formação de um senso de justiça. É dessa forma que, a meu ver, podemos falar de uma "escolha" por uma disposição moral. "Escolher" ser movido por disposições morais, no sentido que proponho aqui, significa endossar e apoiar publicamente as instituições sociais que contribuem para a formação e consolidação dessas mesmas disposições.

Essa tese pode ser elucidada um pouco melhor ao compararmos disposições morais com um tipo similar de disposição, a saber: a motivação religiosa. Estados democráticos modernos reconhecem, de modo geral, o valor da "liberdade de consciência" como um tipo de direito fundamental de qualquer indivíduo. (Esse tipo de direito é respaldado pelo Artigo 18 da Declaração Universal dos Direitos Humanos. $)^{28}$ No entanto, embora esse direito fundamental permita aos indivíduos aderirem livremente às práticas religiosas que quiserem, na verdade, a maior parte das pessoas não endossa uma concepção religiosa de mundo por força de uma "escolha". A adesão a uma prática religiosa é, na maior parte dos casos, circunstanciada pelo ambiente em que um indivíduo nasce e é socializado. Nesse sentido, evidentemente, uma pessoa não "escolhe" realmente ser movida pelas motivações religiosas que, de fato, possui. Ela é motivada por disposições religiosas próprias, por exemplo, de um

making one a welcome participant in cooperative ventures. No one wants a person who altogether lacks a sense of justice as a fellow cooperator, for such a person may not reasonably be expected to be adequaltely disposed to uphold the terms on which interaction is mutually desirable. Even persons who would cooperate in order to victimize others wish for fair dealing among themselves. Since social cooperation is necessary if human beings are to survive, reproduce, and flourish, we may suppose that each person will want her fellows to possess a sense of justice, will prefer to interact with others possessing such a sense rather than others lacking it, and will want herself to possess a sense of justice as it increases their willingness to interact with her and so affords her a fuller realization of her own concerns."

27 Examino essa dificuldade da teoria moral de Gauthier de modo mais detido em Marcelo de ARAUJO (2007a).

${ }_{28}$ Universal Declaration of Human Rights (1948), Article 18: "Everyone has the right to freedom of thought, conscience and religion; this right includes freedom to change his religion or belief, and freedom, either alone or in community with others and in public or private, to manifest his religion or belief in teaching, practice, worship and observance." 
cristão, de um muçulmano, ou de um judeu, não porque "decidiu" adotar essas disposições, mas porque foi socializada no seio de uma cultura cristã, muçulmana, judaica, etc. Por outro lado, na medida em que essa mesma pessoa apóia ou endossa publicamente as instituições sociais que determinaram a formação desse aspecto de seu caráter, e supondo, além disso, que ela tenha o direito fundamental de não apoiar ou endossar tais instituições, podemos dizer que ela "escolhe", em um outro sentido, ter as motivações religiosas que tem. A escolha em questão aqui concerne ao apoio e endosso às instituições que desempenham um papel crucial na formação do caráter de um indivíduo. Dessa forma, um indivíduo "escolhe" tornar-se uma pessoa movida por tais e tais disposições morais, na medida em que ela apóia publicamente as instituições que fomentam, em outros indivíduos, a formação dessas mesmas disposições.

Um senso de justiça, portanto, não apenas motiva um indivíduo a obedecer a lei positiva, mesmo quando não está sendo observado. Um senso de justiça também motiva o indivíduo a apoiar e endossar publicamente as instituições que subjazem à própria formação de um senso de justiça. ${ }^{29} \mathrm{Com}$ efeito, seria estranho que a mesma pessoa que, por um lado, cumpre suas obrigações, mesmo quando não está sendo observada, fosse, por outro lado, inteiramente indiferente à preservação das instituições que, pelo menos em parte, lhe permitiram adquirir um senso de justiça. Dentre as instituições que contribuem para a formação de disposições morais nos indivíduos o direito é, a meu ver, a mais importante. Como Bentham afirma: "Apenas o direito [law] pode acostumar os homens a curvarem suas cabeças sob o peso da precaução, difícil de suportar inicialmente, porém leve e agradável mais tarde." ${ }^{30} \mathrm{O}$ principal estímulo que um indivíduo inicialmente possui para o cumprimento da lei pode ser a simples aversão às penalidades resultantes da não-realização da ação prescrita pela lei. Mas, gradualmente, ele pode também vir a adquirir uma disposição para cumprir a lei, o que torna então irrelevante para ele a presença ou não do tesemunho de outras no momento em que realiza a ação.

É bem verdade, porém, que, contra essa tese - a de que o direito é a instituição que melhor contribui para a formação de disposições morais nos indivíduos - duas objeções poderiam ser levantadas. A primeira é que não é função do direito promover o desenvolvimento de disposições morais nos indivíudos. A função do direito seria apenas a de garantir a realização da vontade do legislador, quaisquer que sejam as disposições morais em virtude das quais as pessoas possam estar motivadas a agirem ou não agirem em conformidade com a vontade do legislador. A segunda objeção é que a fonte de nossas disposições morais não deveria ser buscada na instituição do direito, mas, antes,

\footnotetext{
${ }^{29}$ Cf. GAUTHIER (1993, p. 193): “The sense of justice must then afford its possessor strong affective support for maintaining and adhering to the terms of cooperation, and create in her the desire and expectation that others will show similar support."

30 BENTHAM (1975, p. 67). O texto original é o seguinte: "Law alone can accustom men to bow their heads under the yoke of foresight, hard at first to bear, but afterwards light and agreeable."
} 
em uma série de outras instituições, tais como, por exemplo: na família, em um determinado sistema de educação, no pertencimento a uma determinada comunidade religiosa, ou, de modo geral, na cultura caracterísitica do modus vivendi de uma sociedade, tal como essa cultura se manifesta, por exemplo, em obras literárias, filmes, documentários, etc.

As duas objeções são, a meu ver, justificadas. No entanto, é importante notar que é sobretudo por meio da instituição do direito que essa diversidade de instituições tem a configuração que tem. Mesmo a instituição da família está sujeita às determinações do direito, pois cabe à vontade do legislador decidir, por exemplo, o que conta como "família", i.e. se um casal homossexual, ou se um homem e uma mulher com síndrome de Down estariam habilitados a fundar uma "família". Cabe também à vontade do legislador determinar, por exemplo, se um determinado tipo de manfifestação cultural, em detrimento de outros tipos, deve receber algum tipo de fomento. Ao endossar e apoiar publicamente as leis positivas que regulam a configuração e existência de um amplo espectro de instituições, um indivíduo escolhe fomentar, em outros indivíduos, as disposições que são promovidas por essas mesmas instituições. Se não está realmente em poder de um indivíduo escolher para si próprio as disposições morais que de fato tem, está em seu poder, ainda assim, endossar e apoiar as instituições que contribuem para a formação dessas mesmas disposições em outros indivíduos. A tese (ii), portanto, é insustentável, pois mesmo considerando que apenas disposições morais tais como honestidade ou um senso de justiça garantem que indivíduos obedecerão à lei positiva mesmo quando não estiverem sendo observados, não é necessário explicarmos a racionalidade dessas disposições em termos metafísicos, como inclinações inerentes à própria "natureza" humana. Elas podem ser explicadas em termos de uma escolha racional, no sentido de "escolha" que procurei elucidar acima. Mas podemos nos perguntar agora se a tese (i) também é igualmente insustentável.

A existência de uma lei, por si só, não implica na existência de uma obrigação de obedecer a lei. O obscurecimento da distinção entre o "estar obrigado a" e o "ter a obrigação de" parece ter levado muitos autores à suposição de que existe uma espécie de conexão necessária entre o conceito de lei e o de justiça, uma vez que apenas leis justas geram para nós obrigações. No entanto, a constatação de que apenas leis justas geram obrigações - e portanto a constação de que não apenas não temos a obrigação de obedecermos leis injustas, mas também a de que temos mesmo a obrigação de nos opormos a tais leis - não é um indício de que haja uma relação necessária entre o direito e a moral. Pelo contrário, como procurei deixar claro neste artigo, é justamente a possibilidade de desvincularmos a pergunta sobre o fundamento de nossas obrigações para obedecermos as leis da pergunta sobre o que torna possível a existência de uma lei que nos permite examinar a legitimidade das leis positivas. A tese (i), portanto, é também insustentável. 


\section{Bibliografia}

ALEXY, Robert: "On the necessary relations between law and morality", in Ratio Juris, vol. 2, 1989, p. 167-83.

AQUINO, Tomás de: Suma Teológica, trad. Aldo Vannucchi et alia, São Paulo, Loyola, vol. 4, 2005.

ARAUJO, Marcelo de: "O conceito de pessoa na teoria moral contratualista: uma crítica a David Gauthier", in Síntese, vol. 34, 2007a, p. 55-77.

"Utilitarismo teológico e positivismo legal no pensamento de John Austin", in (org.) Maria Cecília M. de Carvalho, O Utilitarismo em Foco: Um Encontro com Seus Proponentes e Críticos, Florianópolis, Universidade Federal de Santa Catarina, 2007b, p. 39-72.

AUSTIN, John: The Province of Jurisprudence Determined (1832), Cambridge, Cambridge University Press, 1995.

BENTHAM, Jeremy: "Anarchical Fallacies", in (org.) J. Waldron, Nonsense upon Stilts: Bentham, Burke and Marx on the Rights of the Man, Londres, Metheuen, 1987, p. 46-76.

. Introduction to the Principles of Morals and Legislation, Londres, Athlone, 1970.

. The Theory of Legislation, New York, Oceana Publications, 1975.

BIX, Brian: "Natural law theory", in A Companion to Philosophy of Law and Legal Theory, (org.) Dennis Patterson, Oxford, Blackwell, 1996, p. 223-240.

D'ENTRÈVES, A. P.: Natural Law: An Historical Survey, New York, Harper Torchbooks, 1951.

EPIKUR (EPICURO): Wege zum Glück, (org. e trad. dos frag. gregos e latinos ) Rainer Nickel, Düsseldorf / Zurique, Artemis \& Winkler, 2003.

FULLER, Lon: The Morality of Law, New Haven, Yale University Press, 1967.

GAGARIN, Michael: Antiphon the Athenian: Oratory, Law, and Justice in the Age of te Sophists, Texas, The University of Texas Press, 2002.

GAUTHIER, David: Morals by Agreement, Oxford, Oxford University Press, 1986.

. "Value, reasons, and the sense of justice", in (org.) R. G. Frey e C. W. Morris, Value, Welfare, and Morality, Cambridge, Cambridge University Press, 1993, p. 180-208.

168.

'Are we moral debtors?', in Philosophy and Phenomenological Research, vol. 66, 2003, 162-

GILBERT, Margaret: A Theory of Political Obligation: Membership, Commitment, and the Bonds of Society, Oxford, Oxford, University Press, 2006.

GREENWALT, Kent: "Too thin and too rich", in (org.) Robert P. George, The Autonomy of Law: Essays on Legal Positivism, Oxford University Press, 1999, p. 1-30.

HART, H. L. A.: "Legal and moral obligation", in (org.) A. I. Melden, Essays in Moral Philosophy, Seattle / Londres, University of Washington Press, 1958, p. 82-107.

The Concept of Law, Oxford, Clarendon Press, 1961.

HÖFFE, Otfried: Politische Gerechtigkeit: Grundlegung einer kritischen Philosophie von Recht und Staat, Frankfurt, Suhrkamp, 1987.

HOERSTER, Norbert: Verteidigung des Rechtspositivismus, Frankfurt, Alfred Metzner Verlag, 1989. 
."Ein philosophischer Sieg über den Rechtspositivismus?", in (org.) W. Kersting, Gerechtigkeit als Tausch? Auseinandersetzungen mit der politischen Philosophie Otfried Höffers, Frankfurt, , Suhrkamp, 1997, p. 321-330.

KAHN, Charles: "Greek religion and philosophy in the Sisyphus Fragment", in Phronesis, vol. 42, 1997, p. 247-262.

KANT: Grundlegung zur Metaphysik der Sitten, Stuttgart, Reclam, 1984.

KELSEN, Hans: Reine Rechtslehre, Viena, Verlag Franz Deuticke, 1960.

KRIEGER, Leonard: "Kant and the crisis of natural law", in Journal of the History of Ideas, vol. 26, 1965, p. 191-210.

LACEY, Nicola: A Life of H. L. A. Hart: The Nightmare and the Noble Dream, Oxford, Oxford University Press, 2006

MACCORMICK, Neil: "Natural law and the separation of law and morals", in Natural Law Theory: Contemporary Essays, (org.) R. George, Oxford, Clarendon Press, 1994, p 105-133.

MILL, J. S.: Utilitarianism, Oxford, Oxford University Press, 1998.

PLATÃO: República, trad. Maria H. da R. Pereira, Lisboa, Fundação Calouste Gulbenkian, 1987.

RADBRUCH, Gustav: "Gesetzliches Unrecht und übergesetzliches Recht", in Süddeutsche Juristenzeitung, 1946, p. 107.

REID, Thomas: Inquiry and Essays, Indianapolis, Hackett Publishing, 1983.

STEMMER, Peter : Handeln zugunsten anderer: Eine moralphilosophische Untersuchung, Berlim, De Gruyter, 2000.

. "O Contratualismo Moral", (trad. Dario Teixeira e Marcelo de Araujo), in Ethica, vol. 9, 2004, p. 203-226. (Originalmente publicado em Zeitschrift für philosophische Forschung, vol. 56, 2002, p. 1 21).

TUCK, Richard: Natural Rights Theories: Their Origin and Development, Cambridge, Cambridge University Press, 1979.

WALDRON, Jeremy: "O positivismo de Kant", in A Dignidade da Legislação, trad. L. C. Borges, São Paulo, Matins Fontes, 2003, 43-76.

WITTGENSTEIN, Ludwig: "Tagebücher": 1914-1916", in Schriften, Frankfurt, Suhrkamp, 1963, p. 89185

."A Lecture on Ethics", in The Philosophical Review, vol. 74, 1965, p. 3-12.

. Vermischte Bemerkungen: Eine Auswahl aus dem Nachlaß, Frankfurt, Suhrkamp, 1994.

Wittgenstein und der Wiener Kreis: Gespräche, aufgezeichnet von Friedrich Waismann, Frankfurt, Suhrkamp, 1996. 